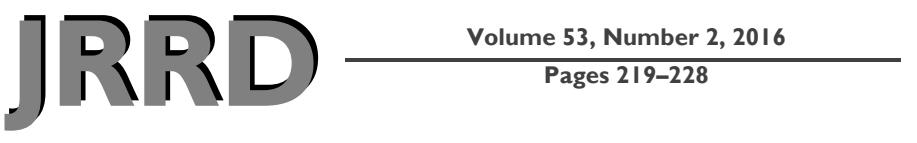

\title{
Plantar pressure displacement after anesthetic motor block and tibial nerve neurotomy in spastic equinovarus foot
}

\author{
Nathalie Khalil, MD; ${ }^{1 *}$ Claudie Chauvière, PT; ${ }^{1}$ Loïc Le Chapelain, MD, PhD; ${ }^{1}$ Hélène Guesdon, MD; ${ }^{1}$ Elodie \\ Speyer, PhD; ${ }^{2}$ Hervé Bouaziz, MD, PhD $;^{3}$ Didier Mainard, MD, PhD $;^{4}$ Jean-Marie Beis, MD, PhD; ${ }^{1}$ Jean Paysant, \\ MD, PhD $^{1}$ \\ ${ }^{1}$ Institut Régional de Médecine Physique et de Réadaptation Nancy, Centre de Médecine Physique et de Réadaptation, \\ Lay Saint Christophe, France; ${ }^{2}$ Service d'Epidémiologie et Evaluation cliniques, ${ }^{3}$ Service d'Anesthésie-réanimation \\ chirurgicale, and ${ }^{4}$ Service de Chirurgie orthopédique, traumatologique et arthroscopique, Centre Hospitalier Univer- \\ sitaire Nancy, Nancy, France
}

\begin{abstract}
The aim of this study was to analyze the displacements of center of pressure (COP) using an in-shoe recording system (F-Scan) before and after motor nerve block and neurotomy of the tibial nerve in spastic equinovarus foot. Thirty-nine patients (age 45 +/- 15 yr) underwent a motor nerve block; 16 (age $38+/-15.2$ yr) had tibial neurotomy, combined with tendinous surgery $(n=9)$. The displacement of the COP (anteroposterior [AP], lateral deviation [LD], posterior margin [PM]) was compared between paretic and nonparetic limbs before and after block and surgery. At baseline, the nonparetic limb had a higher AP (17.3 vs $12.3 \mathrm{~cm}, p<0.001)$ and LD (4.0 vs $3.3 \mathrm{~cm}$, $p=0.001)$ and a smaller PM (2.9 vs $4.7 \mathrm{~cm}, p=0.001)$. For the paretic limb, a significant increase of AP was observed after block (13.5 vs $12.3 \mathrm{~cm}, p=0.02$ ) and after surgery (13.7 vs $12.3 \mathrm{~cm}, p=0.03)$. A significant decrease of PM was observed after surgery ( 4.5 vs $3.3 \mathrm{~cm}, p<0.001)$ with no more difference between two limbs ( $2.8 \mathrm{vs} 3.3 \mathrm{~cm}, p=0.44$ ). This study shows that the F-Scan system can be used to quantify impairments and be useful to evaluate the effects of treatment for spastic foot. It suggests that changes in AP displacement following block may predict the effects of neurotomy.
\end{abstract}

Key words: anesthesic motor block, baropodometry, F-Scan sensor system, gait, hemiplegic, insole sensors, plantar pressure, spastic equinovarus foot, stroke, tibial nerve neurotomy.

\section{INTRODUCTION}

Spastic equinovarus foot is a common deformity that occurs in spastic hemiparesis. The incidence varies between 18 percent [1] and 56 percent [2] 1 yr after stroke. The first-line treatments are physical modalities and injections of botulinum toxin [3]. If this is unsuccessful, surgery involving selective neurotomy of the motor branches of the tibial nerve can be carried out [4-6], with a good long-lasting effect. Most investigators carry out motor nerve blocks prior to surgery [5,7]. Although the importance of preoperative criteria and the evaluation of the clinical and functional effects of treatment are widely accepted [8-9], simple, quantitative measures, which can be used in the real-world setting, have been little evaluated. The few existing studies are based on case series. Bollens et al. carried out a systematic review of

\footnotetext{
Abbreviations: $\mathrm{AP}=$ anteroposterior, $\mathrm{COP}=$ center of pressure, $\mathrm{LD}=$ lateral deviation, $\mathrm{PM}=$ posterior margin.

*Address all correspondence to Nathalie Khalil, MD; Institut Régional de Médecine Physique et de Réadaptation de Nancy, Centre de Médecine Physique et de Réadaptation, 4 rue du Professeur Montaut, 54690 Lay Saint Christophe, France; +33(0)3-83-22-22-31; fax: +33(0)3-83-22-22-00.

Email: nathalie.khalil@ugecamne.fr http://dx.doi.org/10.1682/JRRD.2014.11.0298
} 
the literature and suggested that quantitative, validated analysis tools based on the principles of the International Classification of Functioning and Disability should be developed to evaluate the effect of treatments for spastic equinovarus foot, particularly surgical interventions, on function [10].

Baropodometry is a quite easy-to-use method to evaluate changes in plantar pressure during gait using an inshoe system containing pressure sensors (F-Scan system, Tekscan Inc; South Boston, Massachusetts). This system has been validated for determining pressure distribution under constant conditions [11-12]. This system has provided an objective method for obtaining dynamic recordings of the foot center of pressure (COP) or pressure distribution during stance in nondisabled subjects [13], but also in diabetic patients [14]. Two studies have used this system in hemiparetic subjects [15-16]. Valentini et al. studied three parameters of the displacements of the COP: anteroposterior (AP) displacement, lateral deviation (LD), and posterior margin (PM) of foot contact [17]. In the paretic limb, AP displacement of the COP is shortened, the PM of foot contact is increased, and the LD is reduced [16-17]. These parameters are reliable over time (AP displacement and PM of foot contact), and their coefficient of variability is low (AP for the paretic side and to a lesser degree PM and LD). Clinically, lengthening of the AP displacement of the COP is correlated with an improvement in foot progression. A reduction in the LD could be correlated with less stability or use of assistive device, and a reduction in the PM is correlated with improved heel strike at the beginning of stance phase [16]. We also suggest that AP displacement and the PM could be useful parameters to evaluate the effectiveness of treatments for spastic equinovarus, particularly surgical interventions [17].

The aim of this pilot study was to analyze changes in pressure measurements following motor nerve block and selective tibial neurotomy in adults with spastic equinovarus foot.

\section{METHODS}

This study was carried out in a Regional Center for Physical Medicine and Rehabilitation specializing in neurology. The patients provided informed consent for their participation in the evaluations, the motor nerve block, and surgical intervention. The study was approved by the local ethics committee.

\section{Subjects}

The inclusion criteria were (1) spasticity causing equinovarus foot, with or without varus, on clinical examination; (2) independent gait for at least $70 \mathrm{~m}$, with or without an assistive device; (3) age between 18 and $75 \mathrm{yr}$; and (4) failure of first-line treatments such as botulinum toxin injection and physical treatments.

The exclusion criteria included (1) previous surgery for lower-limb spasticity, (2) contraindications to the anesthetic used for the nerve block or general anesthetic for neurotomy, and (3) use of a rigid ankle-foot orthosis or orthopedic shoe that would prevent the pressure analysis in commercially available shoes.

\section{Method}

\section{Experimental Setup and Protocol}

Three baropodometric evaluations were carried out: at baseline, post-block (following motor block of the gastrocnemii nerve) and post-surgery (after selective tibial nerve neurotomy, and additional surgery if necessary).

Data were collected using the F-Scan in-shoe system. It allows people to walk in normal shoes, using an insole measuring device to detect changes in COP displacements or plantar pressures. The sensors are $0.15 \mathrm{~mm}$ thick and contain 960 resistant sensels (Figure 1). Several sizes are available so that they can be used in commercially available shoes. Each sensor is connected to an interface box positioned on the ankle, which in turn is connected to a recording device fixed on the patient's belt (Figure 1). The recording frequency is $50 \mathrm{~Hz}$, and the data are recorded and processed in the system's software (F-Scan Mobile Research 5.72 software). Foot measurements were taken, and the F-Scan insoles were fitted into standardized shoes. The shoes were all the same model and brand (So Good, model Basic, Gèmo Shoes; Frouard, France) for all participants, with appropriate sizing for individuals. The choice was based on the following criteria: low-cost, easy to wear, soft, lightweight, flat, and without an integrated insole. The system was then calibrated for each subject according to manufacturer's guidelines. The gait testing was carried out over a distance of $70 \mathrm{~m}$, inside, on flat ground, at the participant's preferred walking speed. The data analysis was carried out by averaging all the steps once the first and last steps were deleted. All subjects walked at their comfortable walking speed. They did not wear any ankle or foot orthoses during testing, but assistive devices could be used if necessary. We recorded three parameters previously used 

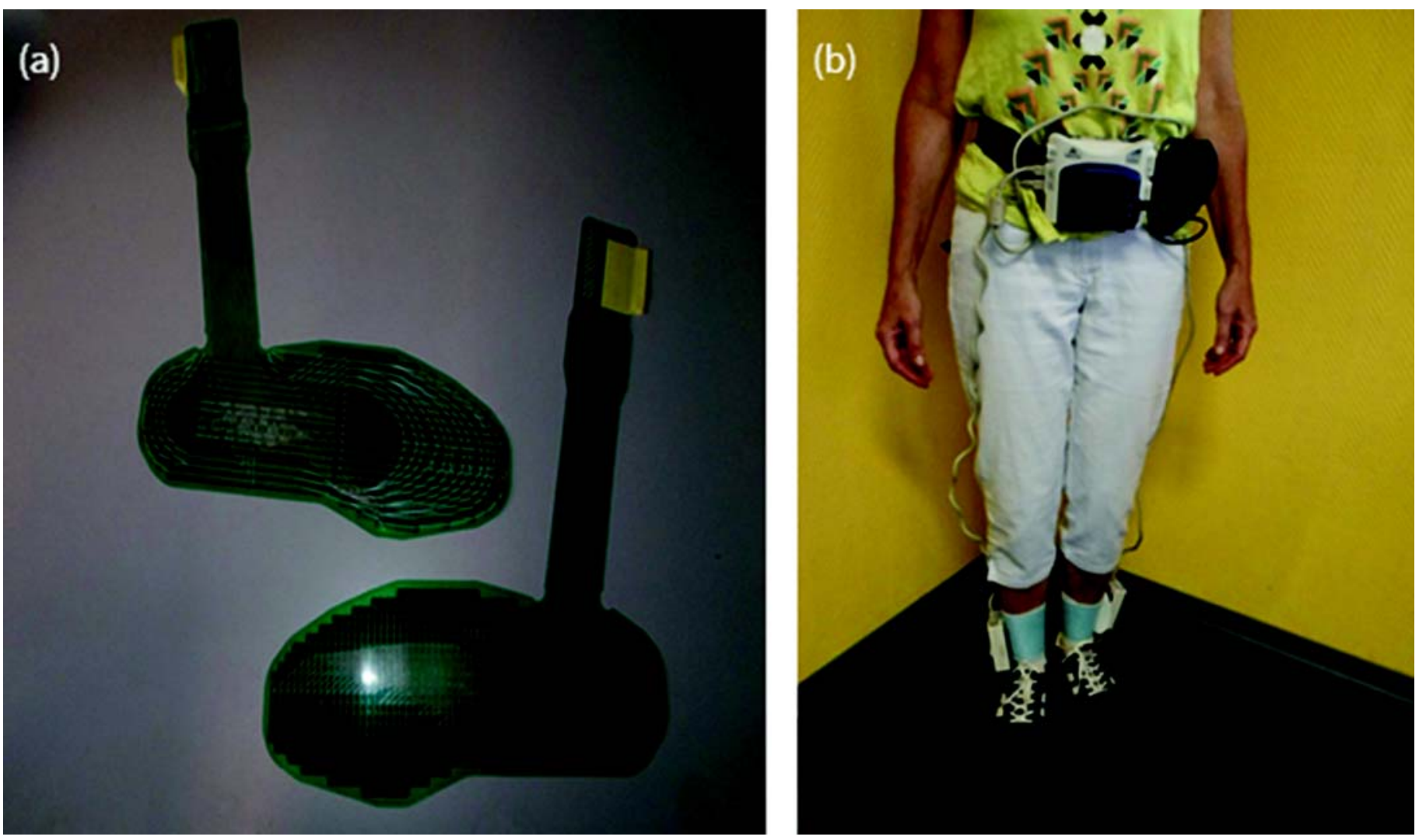

Figure 1.

F-scan system. (a) In-sole sensors with resistant sensels. (b) Interface box positioned on ankle and recording device fixed on belt.

in hemiparetics [17]: (1) AP displacement of the COP measured from the most anterior to the most posterior points, (2) LD of the COP measured from the two most lateral points, and (3) PM of foot contact measured from the most posterior point of heel contact to the most posterior point of the COP trajectory (Figure 2). Each parameter is expressed in centimeters for each foot for each of the three evaluations: at baseline, post-block, and post-surgery.

\section{Motor Nerve Block Procedure}

The anesthetic block was carried out by an anesthesiologist according to the recommendations of the French Society of Anesthesia and Intensive Care [18]. The targets were the nerves of the medial and lateral gastrocnemeii. Ultrasound (SonoSite MTurbo or S Nerve, SonoSite Fujifilm; Bothell, Washington) and neurostimulation (HNS 12, B Braun; Melsungen, Germany) were used to locate the nerves. The local anesthetic used was 2 percent mepivacaine hydrochloride with a volume of 1 to $2 \mathrm{~mL}$ per target.

\section{Surgical Technique}

The selective tibial neurotomies were carried out by a single surgeon, experienced in the technique, under general anesthesia. Following dissection of the tibial nerve trunk and its branches under surgical microscope, the different motor collaterals of the soleus and gastrocnemeii nerves and the posterior tibial nerve were identified. All the collaterals were completely sectioned. Depending on the assessment of the patient's deformities during the multidisciplinary consultation, additional surgery could be performed, for example, neurotomy of the posterior tibial nerve, tenoplasty to lengthen the Achilles tendon, or percutaneous tenotomy of the toe flexors or the hallux (Table 1).

\section{Statistical Analysis}

Descriptive statistics were computed as means, standard deviations, minimum, and maximum for each parameter. Means were compared using Fisher exact test for the qualitative variables and a Wilcoxon signed rank 


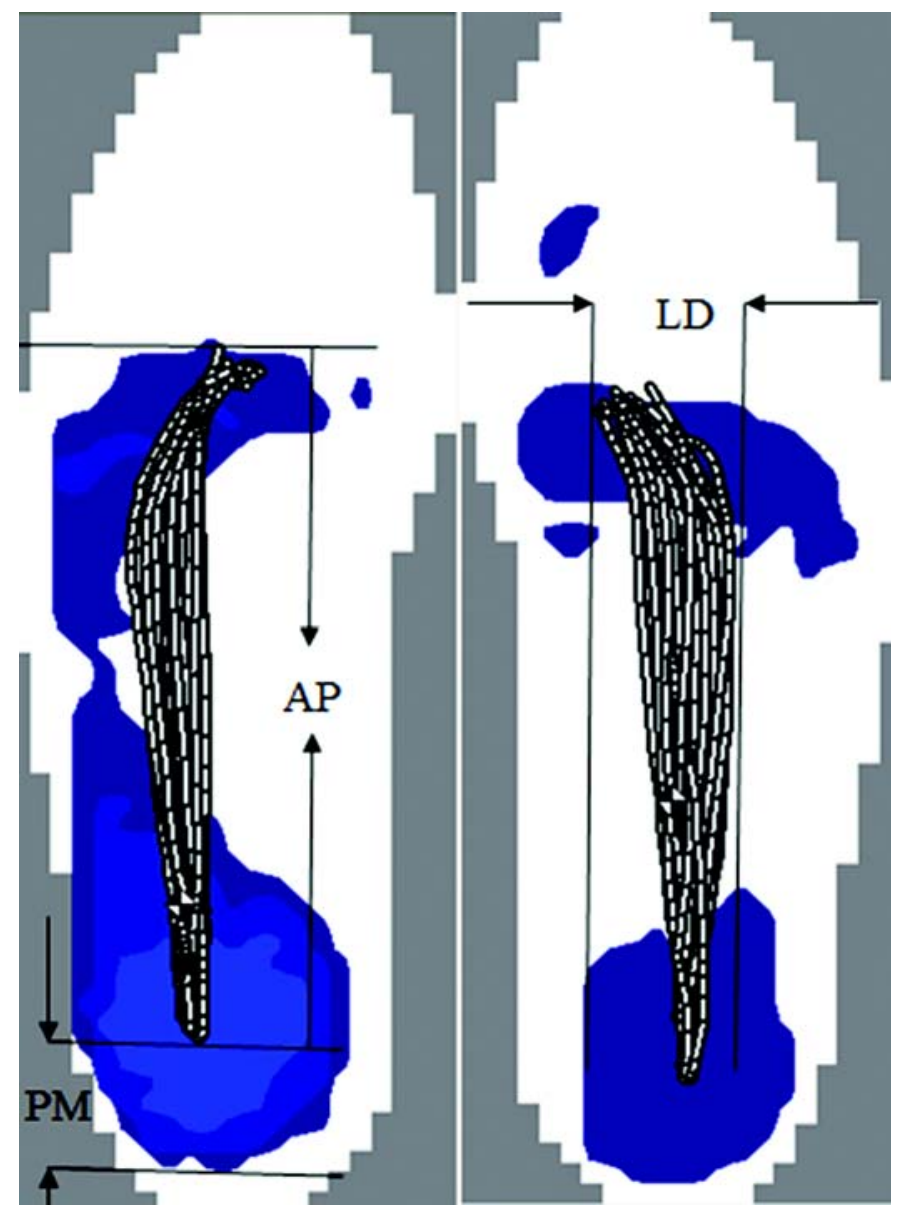

Figure 2.

Center of pressure trajectory of nondisabled subject. AP = anteroposterior displacement, LD = lateral deviation, $\mathrm{PM}=$ posterior margin.

test or Mann-Whitney test for quantitative variables. A threshold of $p<0.05$ was considered significant. The statistical analysis was carried out using SAS version 9.2 (SAS Institute Inc; Cary, North Carolina) software.

\section{RESULTS}

\section{Subjects}

The demographic characteristics of the subjects are summarized in Table 2. Thirty-nine patients underwent assessment at baseline and after motor nerve block. Six patients were excluded because of lack of effect of the motor nerve block on clinical tests or lack of attainment of the functional aim expected following surgery. Surgical
Table 1.

Demographic characteristics at baseline $(N=39)$.

\begin{tabular}{lc}
\hline \multicolumn{1}{c}{ Demographic } & Value \\
\hline Age, yr (mean \pm SD) & $45 \pm 15$ \\
Sex $(n)$ & 20 \\
Male & 19 \\
Female & \\
Side of Paresis $(n)$ & 22 \\
Right & 17 \\
Left & \\
Etiology ( $n)$ & 21 \\
Stroke & 12 \\
$\quad$ Ischemic & 9 \\
$\quad$ Hemorrhagic & 5 \\
Traumatic Brain Injury & 3 \\
Multiple Sclerosis & 3 \\
Strümpell Lorrain & 7 \\
Other & $107.6 \pm 98.9$ \\
Time Since Lesion at Baseline, mo (mean \pm SD) & \\
Assistive Devices $(n)$ & 7 \\
Orthopedic Shoes & 14 \\
Gait Aid (stick) & 9 \\
Ankle Foot Orthosis & \\
Clinical Data & 25 \\
Mean Ashworth Modified Scale (out of 4) on & 2.7 \\
$\quad$ Triceps Surae & \\
Mean Ankle Passive Range of Motion $\left(^{\circ}\right)$ & \\
Mean Ankle Extensors Strength (Medical & \\
$\quad$ Research Council scale out of 5) & \\
Ankle Clonus $(n)$ & \\
\hline SD = standard deviation. & \\
\hline \hline
\end{tabular}

indications were validated in 33 patients, 24 underwent surgery, and 16 participated in all three evaluations at baseline, post-block, and post-surgery (Figure 3). The demographic characteristics and the surgical interventions carried out for these 16 patients are shown in Table 1.

\section{Baropodometric Results}

At baseline, the nonparetic limb had a higher AP displacement (17.3 vs $12.3 \mathrm{~cm}, p<0.001$ ), a higher LD (4.0 vs $3.3 \mathrm{~cm}, p=0.001)$ and a smaller PM $(2.9$ vs $4.7 \mathrm{~cm}$, $p=0.001$ ) compared with the paretic limb (Figure 4).

In the nonparetic limb, there were no statistically significant differences between the three evaluations for any of the parameters evaluated (Figure 5). The longitudinal analysis showed that all three parameters from the nonparetic limb had not statistically changed between the different assessments.

Concerning the paretic limb, a significant increase of length of AP was observed after the motor nerve block 
Table 2.

Demographic characteristics postsurgery $(N=16)$.

\begin{tabular}{|c|c|}
\hline Demographic & Value \\
\hline$\overline{\text { Age, yr (mean } \pm \text { SD) }}$ & $38 \pm 15.2$ \\
\hline \multicolumn{2}{|l|}{$\operatorname{Sex}(n)$} \\
\hline Male & 7 \\
\hline Female & 9 \\
\hline \multicolumn{2}{|l|}{ Paretic Side $(n)$} \\
\hline Right & 11 \\
\hline Left & 5 \\
\hline \multicolumn{2}{|l|}{ Etiology $(n)$} \\
\hline Stroke & 6 \\
\hline Ischemic & 3 \\
\hline Hemorrhagic & 3 \\
\hline Traumatic Brain Injury & 4 \\
\hline Multiple Sclerosis & 2 \\
\hline Other & 4 \\
\hline Time Since Lesion at Postsurgery, mo (mean \pm SD) & $104.1 \pm 90.5$ \\
\hline \multicolumn{2}{|l|}{ Surgical Intervention } \\
\hline Triceps Neurotomy & 16 \\
\hline Triceps and Posterior Tibial Neurotomy & 15 \\
\hline \multicolumn{2}{|l|}{ Additional Surgery to Neurotomy } \\
\hline Achilles Tendon Lengthening & 5 \\
\hline Tenotomy of Toe Flexors & 3 \\
\hline Tenotomy of Toe and Hallux Flexors & 1 \\
\hline \multicolumn{2}{|l|}{ Evaluation Time, mo (mean \pm SD) } \\
\hline Initial Lesion to Surgery & $111.2 \pm 90.3$ \\
\hline Neurotomy to Post-Surgery & $10.7 \pm 6.8$ \\
\hline Block to Surgery & $10.5 \pm 6.7$ \\
\hline
\end{tabular}

for the 39 patients assessed compared with baseline (13.5 vs $12.3 \mathrm{~cm}, p=0.02$ ) and after surgery for the 16 patients assessed (13.7 vs $12.3 \mathrm{~cm}, p=0.03$ ) (Figure 5). No significant change was observed between assessments at baseline and after block for PM. However, a significant decrease of this parameter was observed after surgery ( 4.5 vs $3.3 \mathrm{~cm}, p<0.001$ ) (Figure 5), with no significant difference between nonparetic and paretic limb (2.8 vs $3.3 \mathrm{~cm}, p=0.44$ ) (Figure 4). Finally, the length of LD was not significantly different according to the three assessments.

\section{DISCUSSION}

The principal aim of this pilot study was to analyze changes in pressure measurements following motor nerve block and selective tibial neurotomy in adults with spastic equinovarus foot. We used the F-Scan system to quantify these changes. Previous studies have shown significant changes in the trajectory of the COP between the nonparetic and paretic limbs recorded with the F-Scan system [16-17], but this tool had not yet been used to evaluate treatments.

In this study, the subjects did not wear their own shoes or fittings (orthopedic shoes, ankle foot orthoses) for the assessment. This could be a bias because the patients were not accustomed to the shoes used for the assessment. Nevertheless, we have chosen a unique model of shoes to reduce possible variability between participant shoe type and, moreover, to make sure that all measures (baseline, post-block, and post-surgery) were done with the same shoes for each patient.

Comparison of baropodometric parameters before and after a motor nerve block of the gastrocnemeii nerves showed a significant lengthening of the AP trajectory of the COP following the block, demonstrating better foot progression on the paretic side. Following surgery, the mean length of the AP trajectory on the paretic side was also significantly lengthened and the mean length of the MP was significantly reduced, demonstrating an improvement of heel strike at the beginning of stance phase [16] (Figure 6). Moreover, prior to surgery there was a significant difference in the length of the PM between the nonparetic and paretic sides, which was no longer the case following surgery.

Nevertheless, we must underline as a limit the heterogeneity of the population and the heterogeneity of surgery. Concerning the population, several etiologies were reported as a cause of spastic equinovarus foot. Concerning surgery, all patients underwent a tibial nerve neurotomy $(n=16)$, with some of them $(n=9)$ having additional surgeries. Therefore, this additional surgery could have potential confounding effects. For instance, the reduction of PM can also be explained by tenoplasty to lengthen the Achilles tendon. Further studies in larger samples should be carried out comparing results after neurotomy alone and neurotomy with additional surgeries. Nevertheless, this improvement in weight-bearing symmetry between the nonparetic and paretic sides confirms that the surgery improved heel strike.

Therefore, the F-scan system can be used to evaluate changes in pressure following motor nerve block and surgery and to measure the effectiveness of these two treatments using objective, quantified parameters (these parameters have previously been found to be repeatable and to have low variability in a noninterventional study [17]). More specifically, the AP displacement of the trajectory of the COP, which has been shown to have good 


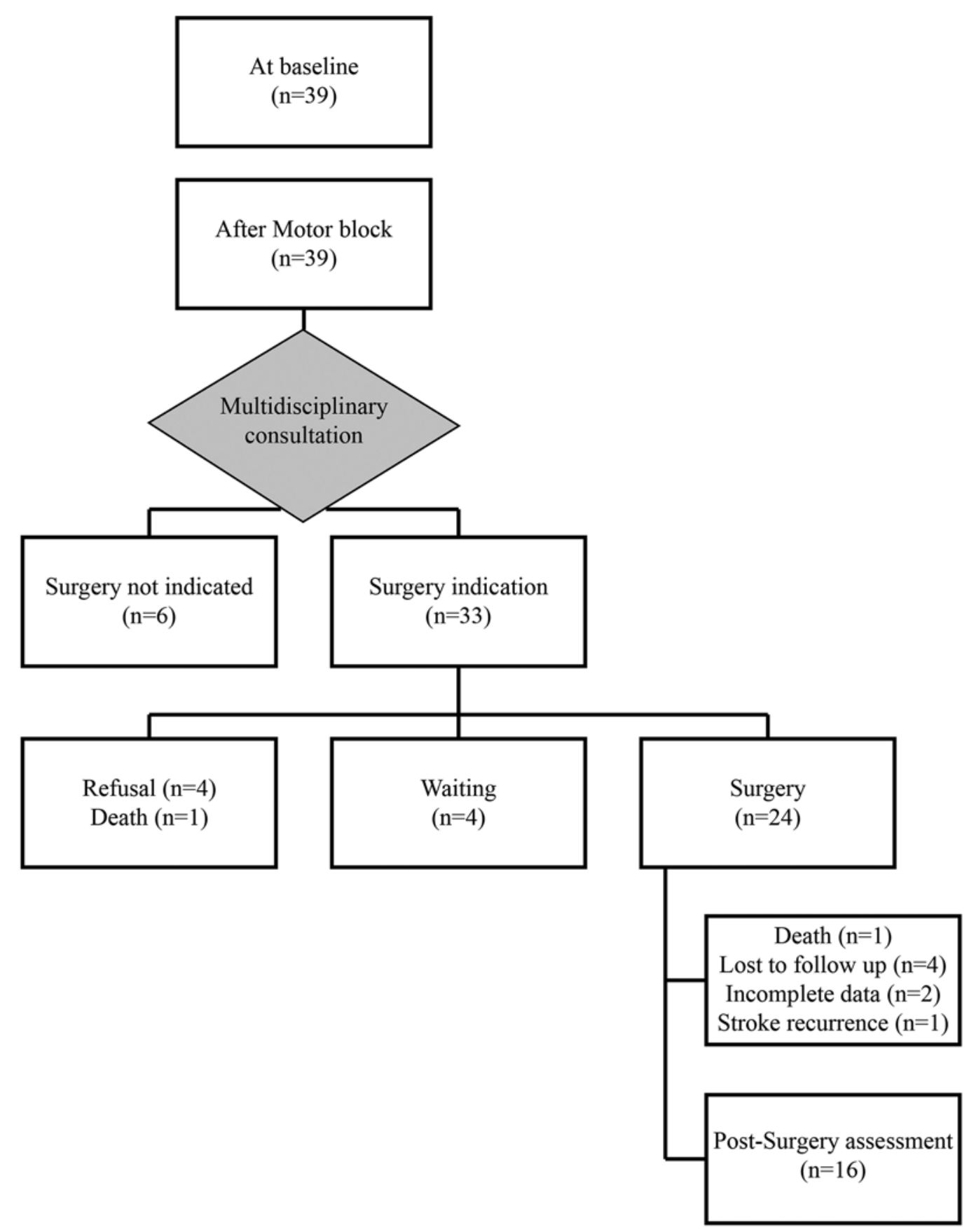

Figure 3.

Study flowchart.

repeatability [17], was significantly improved following motor nerve block and selective neurotomy in the present study. These quantified parameters could be compared or used in addition to other quantitative measures of gait recovery used in hemiparesis like walking speed, percent- age of time spent in double and single limb support, stance, and swing phases [19-21]. Motor nerve block of the tibial nerve branches is predictive of the results of selective tibial neurotomy [22-23]. However, the baropodometric trajectory of the COP recorded in the present study following 

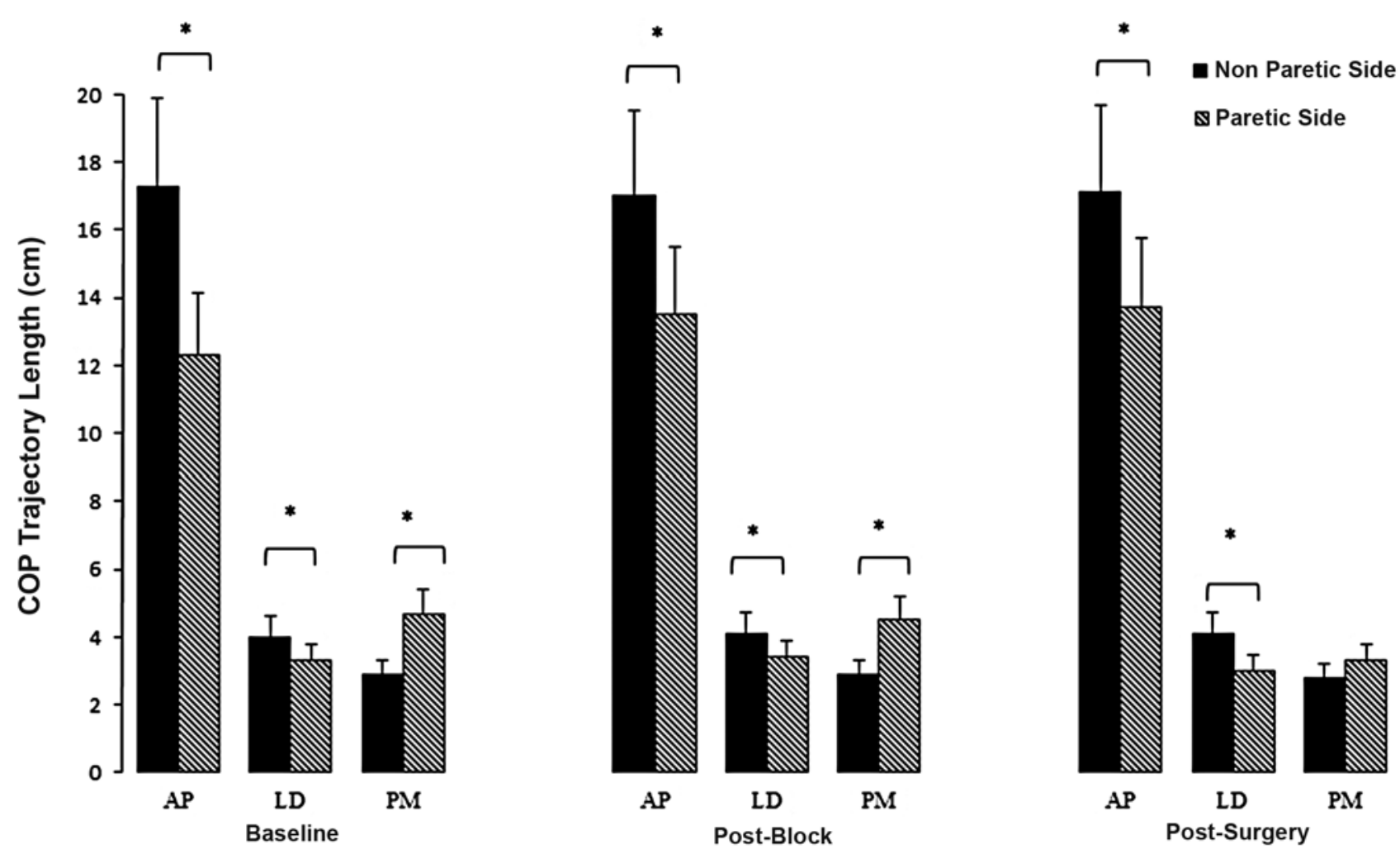

COP Trajectory Parameters

Figure 4.

Comparison of mean center of pressure (COP) displacement between nonparetic and paretic sides at baseline, post-block, and post-surgery $(n=16) .{ }^{*} p<0.05$. Comparison between two evaluations using Wilcoxon signed rank test. AP = length of anteroposterior displacement of COP, LD = lateral deviation of COP trajectory, PM = length of posterior margin of COP.

motor nerve block of the gastrocnemius nerves cannot be directly compared with that measured following surgery because the interventions target different nerves. Nevertheless, the nerve block is useful for surgical decision-making.

The AP displacement of the COP is therefore useful to quantify improvements in foot progression following motor nerve block and selective tibial neurotomy. This parameter could be a predictive marker for the effect of selective tibial neurotomy on foot progression, depending on the baropodometric results following motor nerve block. Correlation studies in larger samples should be carried out to confirm this.

Other studies of neurotomy have reported similar results to the present study; however, most were case studies or evaluated other parameters, such as a recent randomized controlled study that compared the degree of ankle viscoelasticity, gait, and quality of life following botulinum toxin injection and tibial neurotomy [24]. Moreover, in the present study, the patients underwent a complete section of the motor fibers of the soleus and gastrocnemius nerve branches, although partial sectioning of the fibers and sparing of the gastrocnemius nerve is usually recommended as a first-line treatment [5]. Thus, the surgical technique used in this study is an original technique that should be compared with the other techniques currently described in the literature.

\section{CONCLUSIONS}

The in-sole baropodometric system revealed differences in the trajectory of the COP between the nonparetic and paretic limbs. Motor nerve block of the gastrocnemius nerves and the surgical technique improved the 


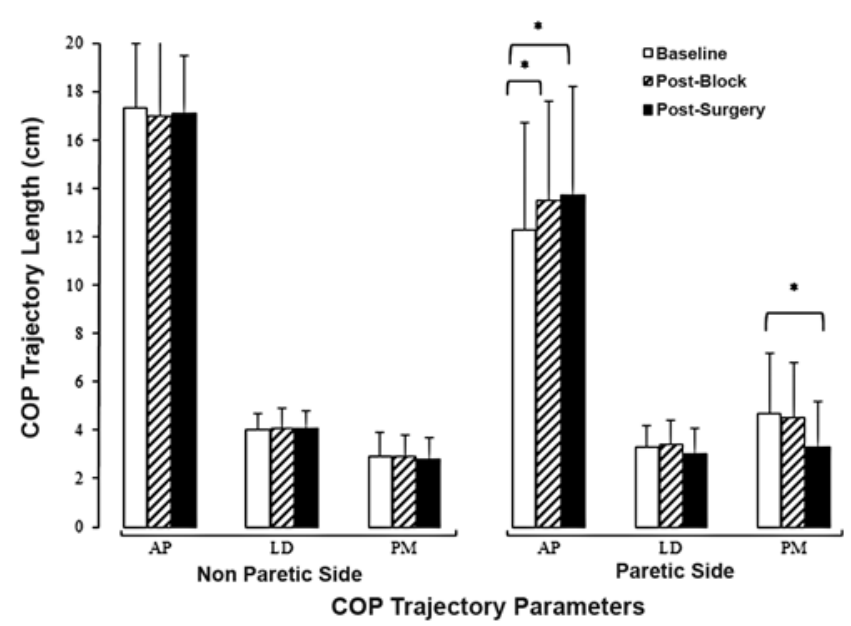

Figure 5.

Comparison of mean center of pressure (COP) displacement at baseline, post-block, and post-surgery on nonparetic and paretic sides $(n=16) .{ }^{*} p<0.05$. Comparison between two evaluations using Wilcoxon signed rank test. AP = length of anteroposterior displacement of COP, LD = lateral deviation of COP trajectory, $\mathrm{PM}=$ length of posterior margin of COP.

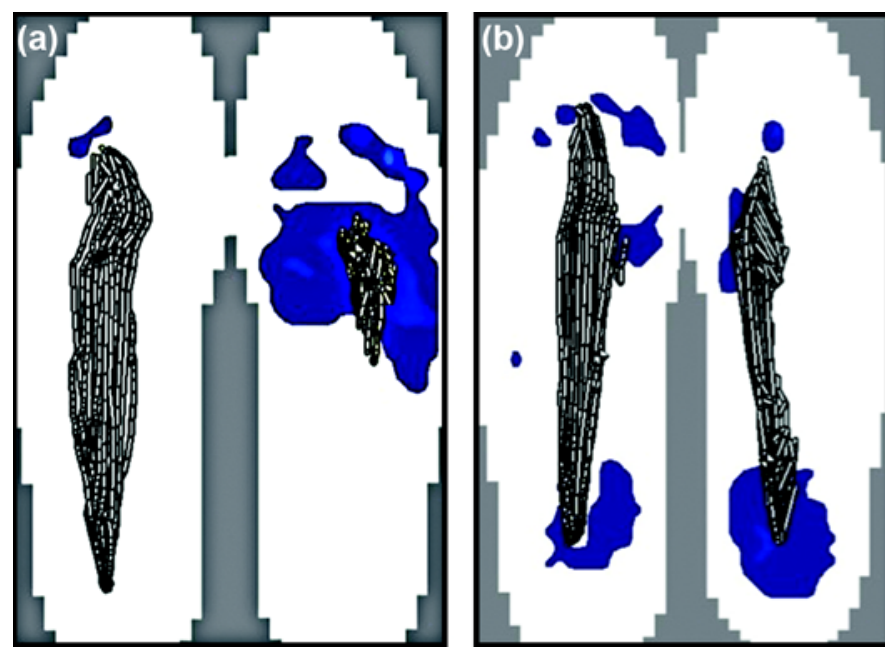

Figure 6.

Example of center of pressure trajectory of right hemiparetic patient (a) at baseline and (b) post-surgery (neurotomy of triceps surae and tibialis posterior). length of the COP trajectory on the paretic side. These preliminary results of this pilot study corroborate current results in the literature on the use of this system for the dynamic evaluation of weight bearing during gait in hemiparetic subjects. To our knowledge, this is the first study to use the F-scan in-sole system to evaluate the effects of motor nerve block and neurotomy on objective quantified parameters in the real-world setting. The results showed that the length of the AP displacement of the COP evaluated the effectiveness of the motor nerve block and the selective tibial neurotomy, and the length of the posterior margin of the COP constituted an objective evaluation of the effectiveness of the selective tibial neurotomy. These preliminary results also suggest that changes in AP displacement of the COP following motor block may predict the effects of neurotomy. Finally, our results should encourage the scientific community to do efficacy studies on this topic.

\section{ACKNOWLEDGMENTS}

\section{Author Contributions:}

Study concept and design: C. Chauvière, L. Le Chapelain, H. Guesdon, H. Bouaziz, J. M. Beis, J. Paysant.

Acquisition of data: N. Khalil, C. Chauvière, H. Guesdon, H. Bouaziz, D. Mainard.

Analysis and interpretation of data: J. M. Beis, J. Paysant.

Drafting of manuscript: N. Khalil.

Critical revision of manuscript for important intellectual content:

E. Speyer, J. M. Beis, J. Paysant.

Statistical analysis: E. Speyer.

Study supervision: N. Khalil.

Financial Disclosures: The authors have declared that no competing interests exits.

Funding/Support: This material was based on work supported by the SORNEST Association (Pierquin-Isch grant).

Additional Contributions: We would like to thank Dr. E. Pourel and Mr. M. Protto for their help with this study.

Institutional Review: All participants were informed of the objectives and nature of the study, which was approved by the Researcher Ethics Committee of the Regional Institute of Rehabilitation of Nancy.

Participant Follow-Up: The authors have no plans to notify the study subjects of the publication of this article because of a lack of contact information.

\section{REFERENCES}

1. Verdié C, Daviet JC, Borie MJ, Popielarz S, Munoz M, Salle JY, Rebeyrotte I, Dudognon P. [Epidemiology of pes 
varus and/or equinus one year after a first cerebral hemisphere stroke: Apropos of a cohort of 86 patients]. Ann Readapt Med Phys. 2004;47(2):81-86. French.

[PMID:15013602]

2. Pélissier J, Viel E, Enjalbert M, Kotzki N, Eledjam JJ. [Chemical neurolysis using alcohol (alcoholization) in the treatment of spasticity in the hemiplegic]. Cah Anesthesiol. 1993;41(2):139-43. French. [PMID:8504349]

3. Wissel J, Ward AB, Erztgaard P, Bensmail D, Hecht MJ, Lejeune TM, Schnider P, Altavista MC, Cavazza S, Deltombe T, Duarte E, Geurts AC, Gracies JM, Haboubi NH, Juan FJ, Kasch H, Kätterer C, Kirazli Y, Manganotti P, Parman Y, Paternostro-Sluga T, Petropoulou K, Prempeh R, Rousseaux M, Slawek J, Tieranta N. European consensus table on the use of botulinum toxin type A in adult spasticity. J Rehabil Med. 2009;41(1):13-25. [PMID:19197564] http://dx.doi.org/10.2340/16501977-0303

4. Buffenoir K, Roujeau T, Lapierre F, Menei P, MenegalliBoggelli D, Mertens P, Decq P. Spastic equinus foot: Multicenter study of the long-term results of tibial neurotomy. Neurosurgery. 2004;55(5):1130-37. [PMID:15509319] http://dx.doi.org/10.1227/01.NEU.0000140840.59586.CF

5. Decq P, Filipetti P, Cubillos A, Slavov V, Lefaucheur JP, Nguyen JP. Soleus neurotomy for treatment of the spastic equinus foot. Groupe d'Evaluation et de Traitement de la Spasticité et de la Dystonie. Neurosurgery. 2000;47(5): 1154-60, discussion 1160-61. [PMID:11063109] http://dx.doi.org/10.1097/00006123-200011000-00027

6. Deltombe T, Gustin T. Selective tibial neurotomy in the treatment of spastic equinovarus foot in hemiplegic patients: A 2-year longitudinal follow-up of 30 cases. Arch Phys Med Rehabil. 2010;91(7):1025-30. [PMID:20599040] http://dx.doi.org/10.1016/j.apmr.2010.04.010

7. Viel E, Pellas F, Ripart J, Pélissier J, Eledjam JJ. [Peripheral nerve blocks and spasticity. Why and how should we use regional blocks?]. Presse Med. 2008;37(12):1793-1801. French. [PMID:18775634] http://dx.doi.org/10.1016/j.lpm.2008.07.007

8. Bensoussan L, Mathelin A, Viton JM, Collado H, Delarque A. Improvement of gait in a stroke patient. A 7-year longitudinal study. Disabil Rehabil. 2010;32(20):1705-11. [PMID:20178412] http://dx.doi.org/10.3109/09638281003649953

9. Deltombe T, Detrembleur C, Hanson P, Gustin T. Selective tibial neurotomy in the treatment of spastic equinovarus foot: A 2-year follow-up of three cases. Am J Phys Med Rehabil. 2006;85(1):82-88. [PMID:16357553] http://dx.doi.org/10.1097/01.phm.0000193506.70371.cf

10. Bollens B, Deltombe T, Detrembleur C, Gustin T, Stoquart G, Lejeune TM. Effects of selective tibial nerve neurotomy as a treatment for adults presenting with spastic equin- ovarus foot: A systematic review. J Rehabil Med. 2011; 43(4):277-82. [PMID:21305231]

http://dx.doi.org/10.2340/16501977-0786

11. Luo ZP, Berglund LJ, An KN. Validation of F-Scan pressure sensor system: A technical note. J Rehabil Res Dev. 1998;35(2):186-91. [PMID:9651890]

12. Sumiya T, Suzuki Y, Kasahara T, Ogata H. Sensing stability and dynamic response of the F-Scan in-shoe sensing system: A technical note. J Rehabil Res Dev. 1998;35(2): 192-200. [PMID:9651891]

13. Brown M, Rudicel S, Esquenazi A. Measurement of dynamic pressures at the shoe-foot interface during normal walking with various foot orthoses using the FSCAN system. Foot Ankle Int. 1996;17(3):152-56. [PMID:8919619] http://dx.doi.org/10.1177/107110079601700306

14. Lord M, Hosein R. Pressure redistribution by molded inserts in diabetic footwear: A pilot study. J Rehabil Res Dev. 1994;31(3):214-21. [PMID:7965879]

15. Han TR, Paik NJ, Im MS. Quantification of the path of center of pressure (COP) using an F-scan in-shoe transducer. Gait Posture. 1999;10(3):248-54. [PMID:10567757] http://dx.doi.org/10.1016/S0966-6362(99)00040-5

16. Robain G, Valentini F, Renard-Deniel S, Chennevelle JM, Piera JB. [A baropodometric parameter to analyze the gait of hemiparetic patients: The path of center of pressure]. Ann Readapt Med Phys. 2006;49(8):609-13. French. [PMID:16780987] http://dx.doi.org/10.1016/j.annrmp.2006.05.002

17. Valentini FA, Granger B, Hennebelle DS, Eythrib N, Robain G. Repeatability and variability of baropodometric and spatio-temporal gait parameters-Results in healthy subjects and in stroke patients. Neurophysiol Clin. 2011; 41(4):181-89. [PMID:22078730] http://dx.doi.org/10.1016/j.neucli.2011.08.004

18. Auroy Y, Bargue L, Benhamou D, Bouaziz H, Ecoffey C, Mercier FJ, Samii K. [Recommendation of the SOS ALR Group on the use of locoregional anesthesia]. Ann Fr Anesth Reanim. 2000;19(8):621-23. French. [PMID:11098327] http://dx.doi.org/10.1016/S0750-7658(00)00271-9

19. von Schroeder HP, Coutts RD, Lyden PD, Billings E Jr, Nickel VL. Gait parameters following stroke: A practical assessment. J Rehabil Res Dev. 1995;32(1):25-31. [PMID:7760264]

20. Turns LJ, Neptune RR, Kautz SA. Relationships between muscle activity and anteroposterior ground reaction forces in hemiparetic walking. Arch Phys Med Rehabil. 2007; 88(9):1127-35. [PMID:17826457] http://dx.doi.org/10.1016/j.apmr.2007.05.027

21. Awad LN, Reisman DS, Kesar TM, Binder-Macleod SA. Targeting paretic propulsion to improve poststroke walking function: A preliminary study. Arch Phys Med Rehabil. 
JRRD, Volume 53, Number 2, 2016

2014;95(5):840-48. [PMID:24378803]

http://dx.doi.org/10.1016/j.apmr.2013.12.012

22. Bleyenheuft C, Detrembleur C, Deltombe T, Fomekong E, Lejeune TM. Quantitative assessment of anaesthetic nerve block and neurotomy in spastic equinus foot: A review of two cases. J Rehabil Med. 2008;40(10):879-81.

[PMID:19242629]

http://dx.doi.org/10.2340/16501977-0263

23. Buffenoir K, Rigoard P, Lefaucheur JP, Filipetti P, Decq P. Lidocaine hyperselective motor blocks of the triceps surae nerves: Role of the soleus versus gastrocnemius on triceps spasticity and predictive value of the soleus motor block on the result of selective tibial neurotomy. Am J Phys Med Rehabil. 2008;87(4):292-304. [PMID:18356621] http://dx.doi.org/10.1097/PHM.0b013e318168bccb

24. Bollens B, Gustin T, Stoquart G, Detrembleur C, Lejeune T, Deltombe T. A randomized controlled trial of selective neurotomy versus botulinum toxin for spastic equinovarus foot after stroke. Neurorehabil Neural Repair. 2013;27(8):
695-703. [PMID:23757297]

http://dx.doi.org/10.1177/1545968313491002

Submitted for publication November 29, 2014. Accepted in revised form July 1, 2015.

This article and any supplementary material should be cited as follows:

Khalil N, Chauvière C, Le Chapelain L, Guesdon H, Speyer E, Bouaziz H, Mainard D, Beis JM, Paysant J. Plantar pressure displacement after anesthetic motor block and tibial nerve neurotomy in spastic equinovarus foot. J Rehabil Res Dev. 2016;53(2):219-28. http://dx.doi.org/10.1682/JRRD.2014.11.0298

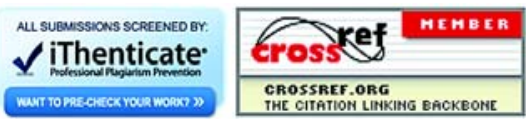

